\title{
ALPHATHESIN, A NEW STEROID ANAESTHETIC AGENT
}

\author{
Jean-Paul Dechêne
}

THIRTY YEARS after Selye in $1941^{1}$ discovered the hypnotic action of various steroids - a discovery which led to the work of Laubach, et al. ${ }^{2}(1954-1955)^{3}$ on 21-hydroxy-pregnanedione sodium succinate (Hydroxydione-Viadril ${ }^{\circledR}$ ) - a new steroid anaesthetic known as "Alphadione," "Althesin" or "Alphathesin" (CT-1341), has now been made available following pharmacological study by K.J. Child, et al. in 1971.4

"Alphathesin" is a mixture of two steroids - alphaxalone and alphadolone - each millilitre containing $9 \mathrm{mg}$ and $3 \mathrm{mg}$ respectively. The purpose of the second steroid alphadolone is to increase the solubility of alphaxalone which is dissolved in cremophor el (polyoxyethylated castor oil).

Studies in animals have shown that CT-1341 acts as a fast, short-duration and dose-related intravenous anaesthetic. Local tolerance is good, and side effects are not significant.

\section{Pharmacological and Clinical Properties}

In 1972, at the Fifth World Congress of Anesthesiology, in Kyoto, Japan, Professors John W. Dundee of Queen's University, Belfast, ${ }^{5}$ Alex Forrester and coworkers of the Royal Infirmary of Glasgow, ${ }^{6}$ and D.G. McDowall of Leeds, ${ }^{7}$ presented papers on Alphathesin: one, on the general aspects of this new steroid anaesthetic; the second, a study on the peripheral vasculature comparing it with sodium thiopentone, and, finally, a third paper on the cerebral effects of Alphathesin. In the same year, the British Post-Graduate Medical Journal published a special issue, entirely devoted to steroid anaesthesia. ${ }^{8}$ It dealt with the contents of a Symposium held at the Royal College of Physicians of London, on January 10 and 11, 1972. In that special issue the general and clinical pharmacology, as well as clinical uses of Althesin, are discussed.

Induction of anaesthesia with Althesin is rapid and directly related to circulation time. The optimum dosage is in the vicinity of $50 \mathrm{ml}$ to $60 \mathrm{ml}$ per kilogram body weight. It appears that, like thiopentone and methohexitone, Alphathesin produces a drop in arterial blood pressure, venous pressure and systolic discharge. The cardiac output remains unchanged because of compensating tachycardia. Respiratory irregularities have been noted with all three anaesthetics, consisting usually of hyperventilation followed by a short period of apnoea and followed by fast shallow breathing. With Alphathesin pulmonary elasticity is apparently improved.

A few muscular movements have been observed on induction of anaesthesia.

Dr. Jean-Paul Dechêne, Associate Professor at McCill University, Director, Dept. of Anaesthesia, Jewish General Hospital, Montreal. 


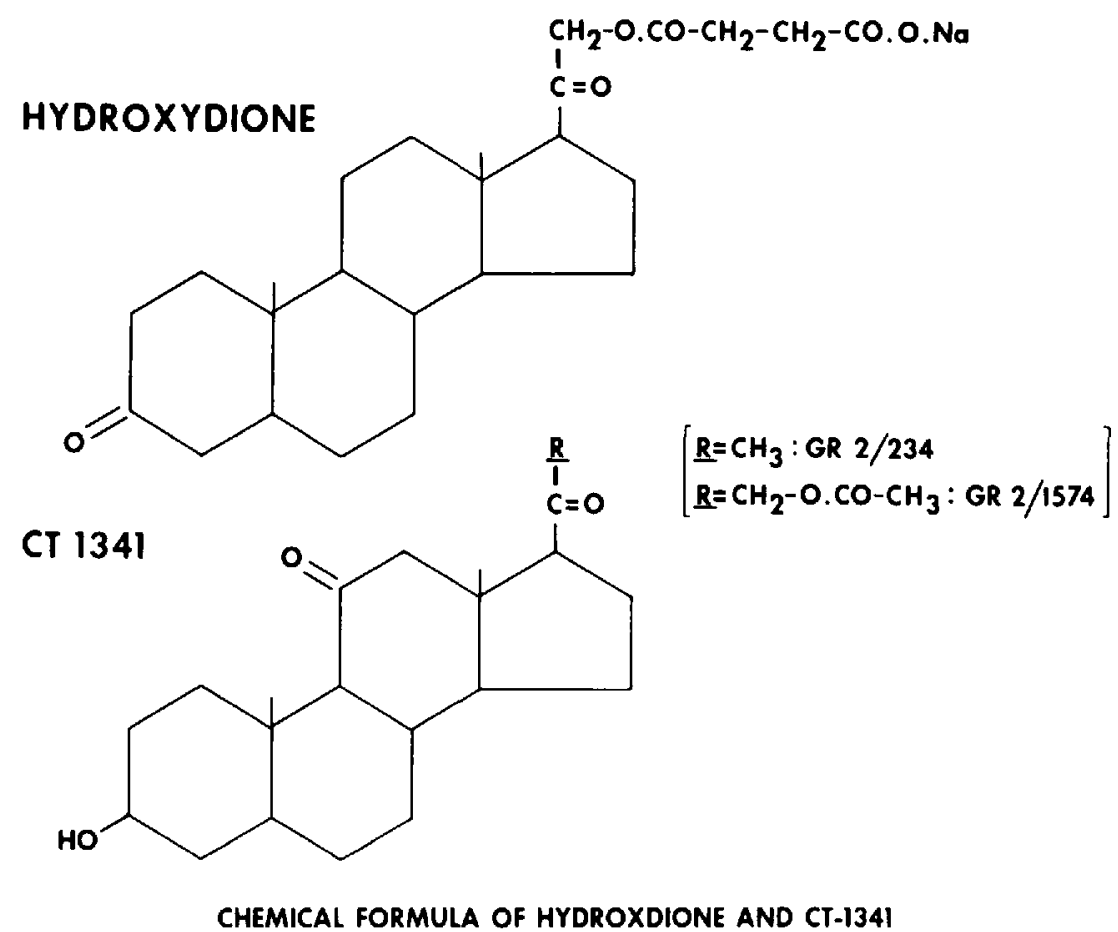

Alphathesin is compatible with succinylcholine. Repeated doses of Alphathesin and of d-tubocurare produce satisfactory operating conditions even for high abdominal operations. Higher doses of Alphathesin will produce longer sleep, particularly in patients over 40 years of age. It has been said that recovery from anaesthesia with Alphathesin is marginally more prolonged than after methohexitone. However, recovery seems complete within 30 minutes and sufficiently quick to make it a valuable anaesthetic for ambulatory surgical patients. Haemodynamic effects of Alphathesin are minimal and, consequently, the agent is indicated in anaesthesia for poor risk patients in a dose range of 30 to 90 microlitres per kilogram. Alphathesin has no effect on the sensory pathways and consequently possesses little analgesic action.

Geddes" has recently suggested that the three main indications for Althesin are anaesthesia for out-patients, endoscopy and X-ray examinations.

\section{STUDY}

Two hundred and twenty patients were anaesthetized with Alphathesin, of whom 150 were out-patients and 70 were in-patients. Their ages ranged between ten and over eighty years. Forty-nine patients were over 60 and forty-three over 70 years of age. This high proportion of geriatric cases is due to the inclusion of 170 urological procedures, in particular cystoscopies. Duration of anaesthesia was from under 30 to over 90 minutes. Cystoscopies accounted for the vast majority of 


\section{HISTOGRAM OF AGE GROUPS}

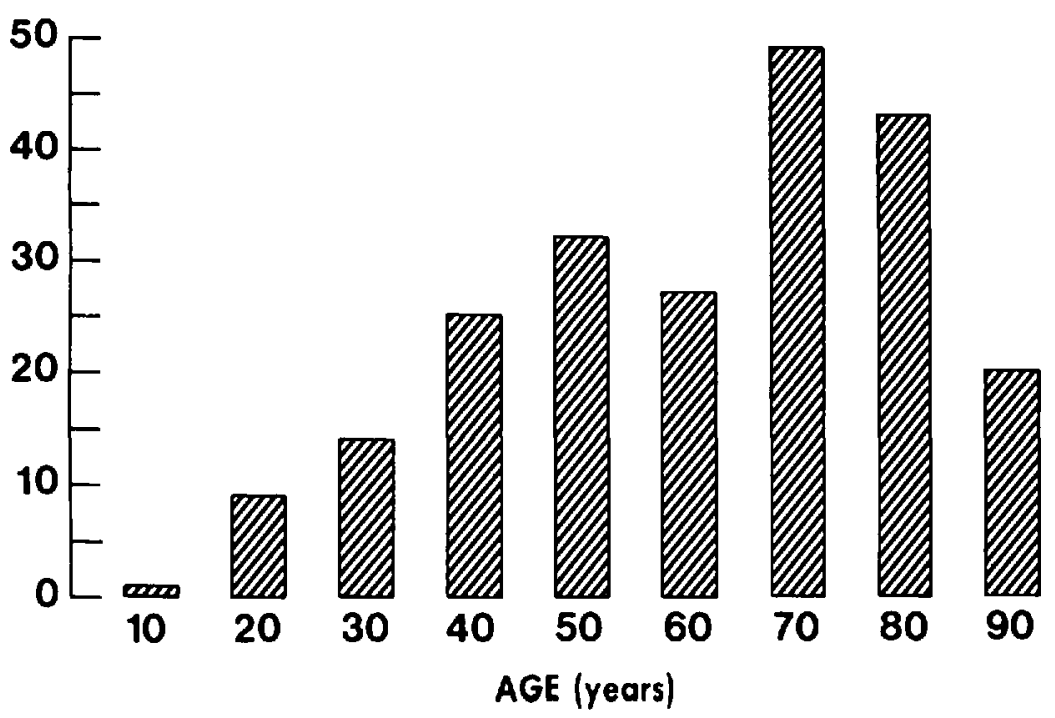

DURATION OF SURGICAL PROCEDURES

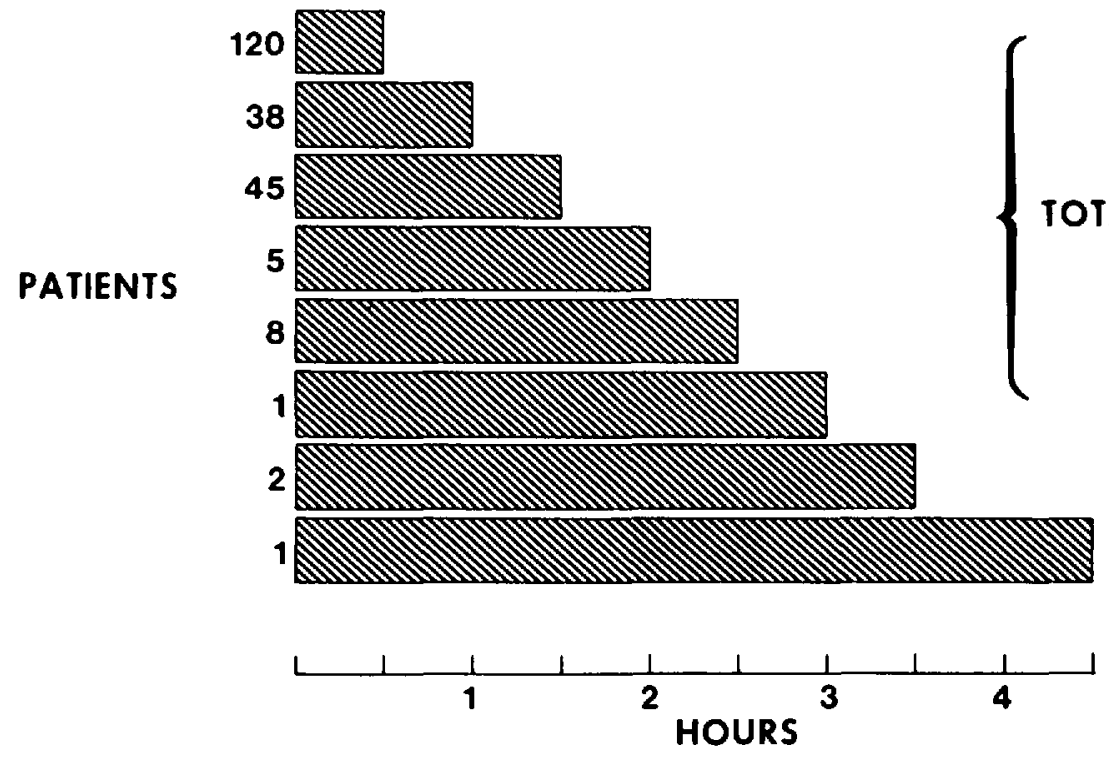

procedures lasting less than 30 minutes. The out-patient group comprised 118 men and 32 women, and the in-patient group 51 men and 19 women.

Apart from the 170 urological procedures, general surgery and gynaecology contributed 12 cases each, ten were orthopaedic operations, eight from ophthalmology, six otorhinolaryngology, and finally two were dental operations. 


\section{TYPE OF SURGERY}

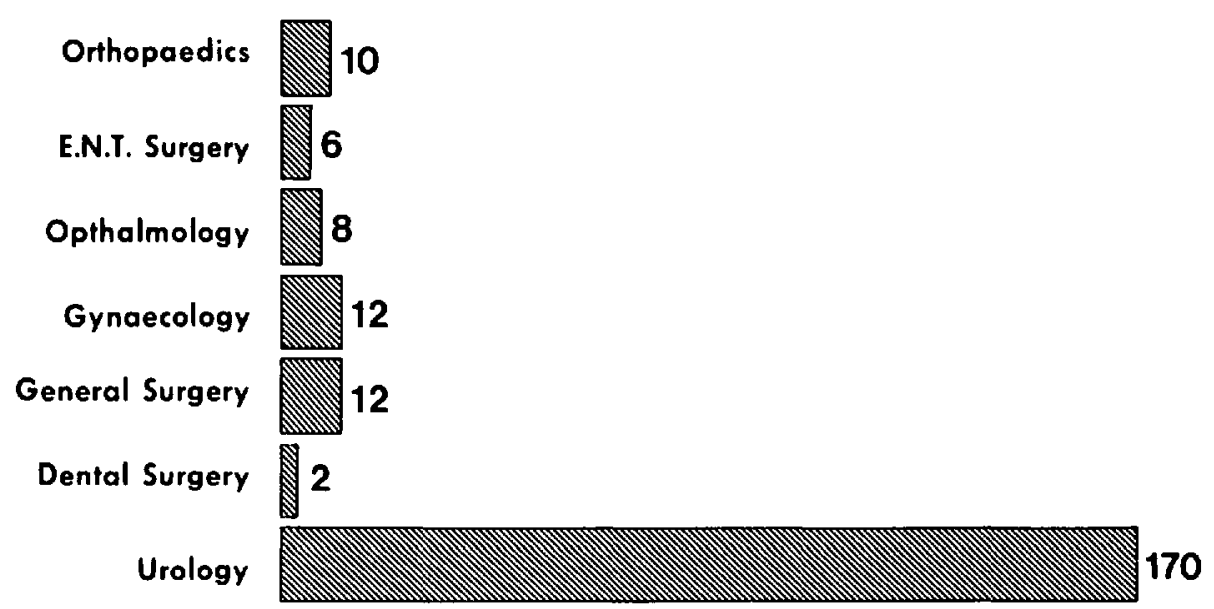

No patient selection was made among patients and none were eliminated in spite of various pathological conditions, as follows:

$\begin{array}{lr}\text { Coronary artery disease } & 35 \text { patients } \\ \text { Chronic respiratory diseases } & 30 \text { patients } \\ \text { Cardiac insufficiency and arrhythmias } & 10 \text { patients } \\ \text { Hypertension } & 5 \text { patients } \\ \text { Diabetes } & 15 \text { patients }\end{array}$

\section{Premedication}

Almost all patients received premedication with atropine. In addition, in-patients were given either diazepam or meperidine.

\section{Anaesthesia}

Alphathesin was used only as a "starter," as a single intravenous injection of 0.50 microlitres, 0.10 microlitres and 0.20 microlitres per kilogram body weight, taking into account the age and physical condition of each patient. More recently an infusion of Alphathesin 0.1 per cent has been tried with success in our institution.

Following induction, anaesthesia has been maintained with another anaesthetic agent. For short interventions which did not require relaxation or much analgesia, halothane together with nitrous oxide and oxygen (50/50) have been the most commonly used annesthetic agents. However, in a certain number of cases we have added diazepam $5 \mathrm{mg}$ intravenously to control muscle tremors which are occasionally seen with Alphathesin. In other instances Alphathesin has been followed by a variety of anaesthetic combinations including halothane, methoxyflurane, neuroleptanalgesia, all with or without curare. 


\section{PATHOLOGY}

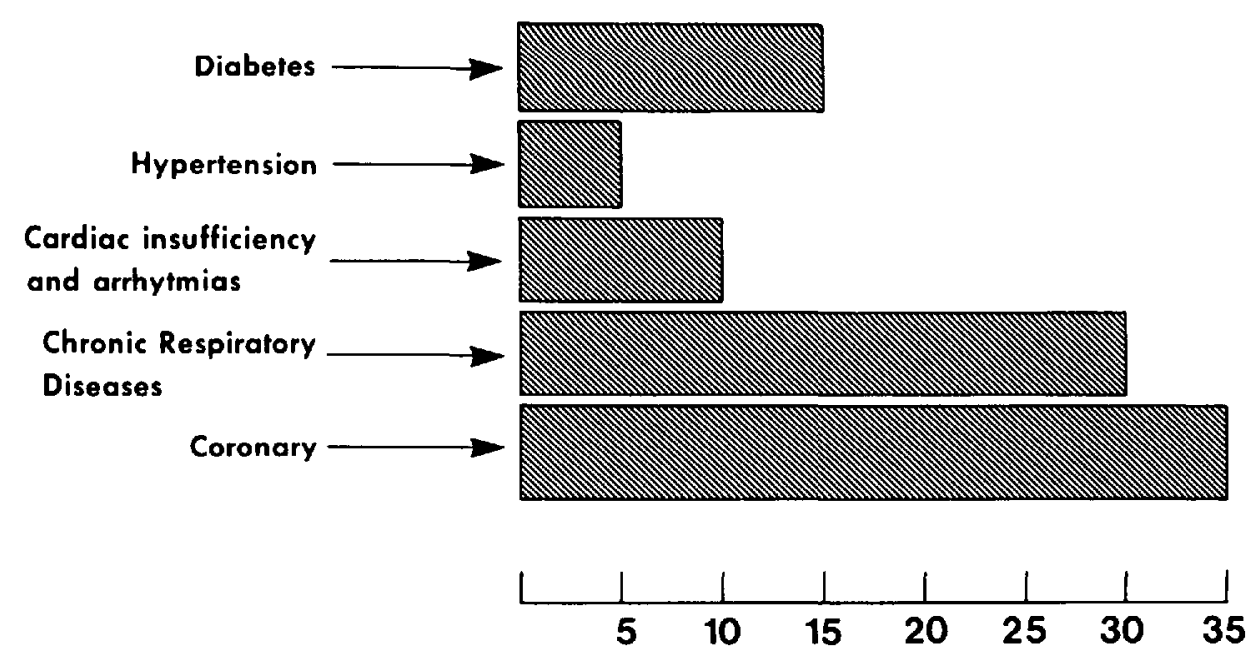

\section{Results and Discussion}

The changes observed following induction of anaesthesia may be considered under the headings of respiratory, cardiovascular and other effects of Alphathesin.

Respiratory effects. Apnoea does not occur in every case. The incidence is related to the speed of injection and in our series was 30 per cent.

Cardiovascular effects. A mild tachycardia is one of the most constant elements among the cardiovascular changes. It occurred in about 35 per cent of our patients. Hypotension of between 10 and $15 \mathrm{~mm} \mathrm{Hg}$ was noticed in 25 per cent of our cases.

Other side-effects. Muscle tremors in the extremities and spasticity were observed in 2 per cent to 3 per cent of our patients. However, these are almost nonexistent if Alphathesin infusion replaces the single or the repeated dose method of administration. None of these tremors were of any consequence as far as completion of anaesthesia and of the surgical operation are concerned.

Recovery from anaesthesia. Three psychomotor tests have been used by various authors to verify postanaesthetic recovery in an objective manner:

(1) The Newman test ${ }^{10}$ explores optico-motor co-ordination by asking the patients to join the dotted lines of a drawing with dashes.

(2) The Horatz numerical test ${ }^{11}$ studies the speed of reaction and the degree of concentration of the individual in the recovery stage; for instance he may be asked to write, as quickly as possible, the figures from 1,000 to 970 .

(3) Finally, the Bourdon letter test ${ }^{12}$ requires the patient to cross as quickly as possible some letters in a given text, for example, the letter "a". Here again, mental concentration, capacity and speed are tested.

Some of our ambulatory patients have been submitted to some of these tests, and 
the results have been conclusive. In agreement with other authors we have found recovery from Alphathesin to be fast and complete.

In the recovery room, when applying the "Aldrete" coding ${ }^{13}$ of recovery, more than 65 per cent of our ambulatory patients reached the maximum 10 points within 30 minutes.

These properties of Alphathesin fulfil many but not all of the criteria for an anaesthetic for operation on out-patients, such as fast action, absence of toxicity, complete recovery, absence of side-effects, and analgesia. The last is the only property missing in the agent. In view of the increasing popularity of out-patient surgery, Alphathesin would seem to merit attention for this purpose.

\section{Conclusion}

This is a study of 220 patients, most of them out-patients, who were anaesthetized with Alphathesin. Although the use of Alphathesin has not been discussed in depth, one can say that it is not a substitute for other intravenous anaesthetics available at the present time. Alphathesin, however, deserves further study as it may be able to supply new solutions to new problems which are encountered daily in our specialty, particularly in the field of out-patient surgery.

\section{RÉSUMÉ}

Dans ce travail intitulé "Evaluation d'un nouvel anesthesique steroidien", sur quelque deux cents cas dont la majorité de Chirurgie Ambulatoire, tous les problèmes soulevés par l'utilisation de l'Alfatésine n’ont certes pas été discutés en profondeur. Cependant, nous pouvons retenir dès maintenant que l'Alfatésine n'est pas un substitut direct des autres anesthésiques intraveineux existantes à l'heure actuelle. L'Alfatésine se doit d'ètre degardée comme une médication originale méritant largement une exploration plus approfondie et pouvant fournir de nouvelles solutions aux problèmes rencontrés quotidiennement dans notre spécialité.

\section{REFERENCES}

1. Seylye, H. Anaesthetic effects of steroid hormones. Proceedings of the Society of Experimental Biology and Medicine 46: 116-121 (1941).

2. LAubach, G.D., P'AN, S.Y., \& Rudel, H.W. Steroid anaesthetic agent. Science 122: 78 (1955).

3. Dechêne, Jean-Paul. L'Anesthésie stéroüde en chirurgie pulmonaire. Union Médicale du Canada 87: 155 (1958).

4. Child, K.J., Cunhie, J.P., Davis, B., Dodds, M.G., Pearce, D.R. \& Twissell, D.J. The pharmacological properties in animals of CT-1341. A new steroid anaesthetic agent. British Journal of Anaesthesia, 43:2 (1971).

5. Dunder, J.W. Althesin (CT-1341): a new steroid intravenous anaesthetic. Miyazaki, Iwatsuki, and Fugita: Anaesthesiology Proceedings of the Fifth World Congress of Anaesthesiologists, Kyoto, September 19-23, 1972, New York: American Gisevier Publishing Co., Inc. 163-167 (1973).

6. Fohrester, A.C., Telfer, A.B.M., \& Young, R.V.B. Peripheral blood flow changes with Althesin and Thiopentone, New York: American Gisevier Publishing Co., Inc. 168-172 (1973). 
7. McDowall, D.G., Pickerodt, V.W.A., Turner, J.M., Coroncos, N.J., Gypson, R.M., Keaney, N.P., Poweld, D., \& Ness, A. The effects of Althesin on cerebral blood flow, cerebral metabolism and intracranial pressure. New York: American Gisevier Publishing Co., Inc. 143-144 (1973).

8. Postgraduate Medical Journal, 48: Suppl. (June 1972) Oxford: Blackwell Scientific Publications Ltd. (1972).

9. Gedpes, I.C. et Dubors, M. Utilisation du CT-1341 Althesin en Grande-Bretagne. Résultats d'un sondage et expérience personnelle, p. 545 (Liverpool et Paris).

10. Laxenaine, M.C., Weber, M., Martinelle, F., Hottier, M.C., et Picard, J.M. Appréciation du réveil par des tests psychomoteurs et l'EEG après anesthésie à l'alfatésine. Symposium Alfatésine, 15-88 (15 février, 1974).

11. Donne, R., Goudot, B., Latanjet, J., Grlle, Y.D., et Bousillon, V.B. L'Alfatésine en urologie. Symposium Alfatésine, 185-194 ( 15 février, 1974).

12. DuCarlar, J. et Rioux, J. Indications du Ct-1341 en anesthésia ambulatoire. Symposium Alfatesine, 209-216 (15 février, 1974).

13. Aldrete, J.A. \& Kroulik, D. A post-anaesthetic recovery score. Anesthesiology. Analg. 49: 924-934 (1970).

Other References:

Annales de l'Anesthesiologie Française, 14e année, No. 6. Bouyard, P., Gotte, G., Mesdjian, E., Gastaut, J.A., Jadot, G., et Martelli, M. Pharmacologie - Place du Ct-1341 (Alfatésine parmi les stéroïdes anesthésiques : ses propriétés pharmacodynamiques, p. 481. Du Cailar, J. Les effets respiratoires du Ct-1341, p. 535 (Montpellier).

Anesthésie, Analgésie, Réanimation, XXIX, No. 4 (juillet-août 1972). Gauthier-Lafaye, J.P., Andrés, M., Masson, J., Beley, Pinelli, J., Gauthier-Lafaye, J., Dupeyron, J.P., et Zimmer, R. Le CT-1341, nouvel agent anesthésique, p. 59.

Aubert, P.A., Freiermuth, C., et Preaux-Maubec, E. Cahiers d'Anesthésiologie, Tome 22, No. 5. Août-septembre 1974. "Anesthésie Générale au CT-1341," p. 539. 